DOI 10.37882/2223-2982.2021.10.04

\title{
НЕКОТОРЫЕ ОСОБЕННОСТИ СИНОНИМИИ ГЛАГОЛОВ В АНГЛИЙСКОМ АВИАЦИОННО-ТЕХНИЧЕСКОМ ТЕКСТЕ
}

\section{SOME PECULIARITIES OF SYNONYM VERBS IN ENGLISH AVIATION TEXT}

O. Anurova

E. Zudilova

Summary: This article presents the analysis of synonym verbs in English aviation texts and the translation peculiarities of such terms from English into Russian when working with technical documentation and manuals for aircraft operation Airbus aircraft (Airbus A-320 Flight Crew Operating Manual). The functioning of the frequently used synonym verbs has been studied on the base of Airbus A-320 Flight Crew Operating Manual. Besides, the synonym verbs inherent to the aviation technical text have been identified.

Keywords: translation, synonyms, aviation, verb, comparative linguistics.
Анурова Ольга Михайловна

к.ф.н., дочент, Московский авиационный институт (Национальный исследовательский университет) kokorewa@rambler.ru

Зудилова Екатерина Николаевна стариий преподаватель, Московский авиационный институm

(Национальный исследовательский университет) e.n.zudilova@gmail.com

Аннотация: Данная статья посвящена анализу синонимов-глаголов в английском авиационно-техническом тексте и особенностям межъязыковой передачи таких терминов с английского языка на русский при работе с технической документацией и руководствами по эксплуатации воздушных судов семейства Airbus. На примере Airbus A-320 Flight Crew Operating Manual рассмотрено функционирование часто встречающихся глаголов синонимов, а также из общего пласта синонимичной лексики выявлены глаголы-синонимы, присущие именно авиационно-техническому тексту.

Ключевые слова: перевод, синонимы, авиация, глагол, сопоставительное языкознание.

дочению терминологии и составлению специальных словарей;

3. недостаточное развитие работ по международному упорядочению терминологии [3, с. 116]

Целью нашего исследования является анализ функционирования часто употребляемых глаголов - синонимов и отбор из огромного пласта синонимов, представленных в словарях, именно тех, которые присущи авиационно-техническому тексту и являются полноценными синонимами, а также могут заменять друг друга в случае необходимости. Таким образом, актуальность данного исследования обусловлена потребностью в комплексном изучении особенностей работы с глаголами-синонимами в авиационной терминологии и систематизации их использования. Результаты данного исследования могут быть полезны как для специалистов переводчиков, так и авиационнотехнического персонала. Объектом исследования послужила выборка английских терминов в авиационной индустрии семейства гражданских пассажирских самолётов Airbus. В качестве материала для исследования использовались несколько примеров терминов и предложений из руководств по эксплуатации данных самолетов. Будут рассмотрены лингвистические особенности таких текстов и особенности их межязыковой передачи.

\section{Метох}

В соответствии с целью и задачами нашего иссле- 
дования был использован целый комплекс различных лингвистических методов, таких как: метод комплексного анализа научно-технической литературы авиационный отрасли, классификация проанализированного материала, метод сплошной выборки, а также метод линзы стилистического анализ.

\section{Исследование}

Основные требования к идеальному термину были разработаны в 70-х в 80-х годах 20 века. Среди таких требований выделяются: однозначность, точность, номинативная функция, отсутствие эмоциональной, экспрессивной и модальной функции, тождество значения термина понятию, стилистическая нейтральность, системность, краткость, соотнесённость со специфическим объектом, известная лишь кругу лиц. [7, с. 16.]. Авиационная терминология является достаточно устоявшейся, основные термины регистрируются в стандартах, но, несмотря на это, при использовании термина встречаются и расхождения, так как при выполнении своих задач специалисты руководствуются не только стандартами, но и другими техническими документами и регламентами. Таким образом, наличие большого числа синонимов вызывает у переводчиков зачастую большие трудности, так как не все представленные в словаре лексемы будут правильно трактоваться и восприниматься специалистами. Важно понимать, что составляет сущность термина, так как термины выступают в качестве объекта в широком диапазоне областей теоретической и прикладной деятельности, каждая из которых выделяет в термине нужные ей аспекты. [6, с. 12.]

В отношении содержательной структуры термина принято говорить о его семантике или значении термина, которое описывается традиционным семантическим треугольником Огдена-Ричардса. С термином как знаком сопоставляются предмет имени (денотат) и понятие о предмете (смысл имени, концепт денотата) [5]. Когда мы говорим о синонимии терминов и рассматриваем определенные понятия, дефиниции, т.е. существительные, мы имеем в виду определенные номинативные единицы. Когда речь идет о глаголах, то здесь при синонимии терминов, мы должны учитывать не только семантику глагола, но и его коннотацию, т.е. сопутствующее значение языковой единицы.

Давайте рассмотрим функционирование русского глагола предполагать в авиационно-техническом контексте. В электронном словаре Мультитран приводится большое количество возможных синонимов для данного русского глагола, однако лингвисты-переводчики могут заметить, что многие из них имеют свое коннотативное значение, а также свою стилистику. Приведем лишь некоторые значения глагола предполагать, в значении делать предположение, допускать возможность чего- либо, указанные в словаре: assume; intend; presuppose; anticipate; expect; suspect; suggest; conjecture; presume; propose; fancy; divine; guess; imagine; imply; make; understand; apprehend; intend; extrapolate ; portend feel (spy); posit; take; iphotize ; plan; surmise; reckon; involve; carry ; connote; envisage; design.

Если мы принимаем во внимание авиационный технический контекст, то стоит отметить, что глагол предполагать зачастую не означает чье-то мнение или суждение, а подразумевает заранее выверенный и просчитанный инженерами авиаконструкторами алгоритм и встречается данный глагол в контексте различных отказов и неисправностей; означает действие, которое предполагается делать в том или ином случае, а также предполагает работу той или иной системы, просчитанную заранее на случай неисправности. Рассмотрим следующие примеры: A runway friction coefficient lower than assumed in computations. [10, p.2436]. Коэффициент трения взлетно-посадочной полосы ниже, чем предполагается в расчетах.

The current vertical deviation VDEV is based on the altitude at which the aircraft is supposed to cross the exit fix in order to be properly positioned on the descent profile. [10, p.974]. Текущее вертикальное отклонение VDEV предполагается на высоте, на которой воздушное судно должно пересечь контрольную точку, чтобы выполнять снижение на постоянной заданной скорости.

Глагол предназначать, предназначаться может иметь следующие некоторые эквиваленты согласно словарю Мультитран: destine; assign; design; intend; mean; allot; allocate; designate; consign; predesignate; doom; predestinate; tab; destinate; intend ; fate; appoint; devise; frame; address ; calculate; pitch;appropriate; earmark; prescribe; dedicate to.

В контексте авиационно-технических текстов этот глагол имеет значение: предписанный согласно действующей инструкции и стандартам (например: предписанная, заданная скорость assigned speed), предназначенное для определенных целей, задач оборудование (dedicated equipment), разработанное и спроектированное изделие, программное обеспечение (designed program). Рассмотрим следующие примеры:

Each crew member uses his dedicated communication equipment [10, p.1124]. Каждый член экипажа использует предназначенное оборудование для обеспечения связи.

The FlySmart with Airbus application suite for Windows is designed to improve access to flight crew's operational information [10, p.3973].

Приложение FlySmart компании Airbus для операционной системы Windows предназначено для оперативного доступа членов экипажа к инструкциям по эксплуатации ВС. 
Глагол облегчать имеет большой спектр англоязычных синонимов в электронном словаре Мультитран. Рассмотрим некоторые из них: ease; relieve ; appease ; alleviate; expedite; mitigate ; soothe; disencumber; solace; allay ; unburden; facilitate; abate; lubricate soften; unload. В авиационно -техническом контексте, помимо общепринятого значения, этот глагол употребляется, в частности, в контексте снижения, уменьшения силовых нагрузок (например, to alleviate the wing structure loads -уменьшать нагрузку на крыло). Рассмотрим следующие примеры: The load alleviation function permits to alleviate the wing structure loads. [10, p.1375]. Функция снижения критической нагрузки позволяет облегчить нагрузку на крыло ВC.

Takeoff must be performed normally, and the rate of climb must be limited to about $500 \mathrm{ft} / \mathrm{min}$, to ease the pressure change felt by passengers and crew. [10, p.3474]. Взлет должен быть выполнен в итатном режиме, при этом скорость при наборе высоты ограничена до 500 футов в минуту, чтобы облегчить нагрузку на пассажиров и членов экипажа из-за смены давления.

Рассмотрим функционирование глагола менять/изменить и синонимичных им лексем, используемых в авиационно-техническом контексте, на примере глаголов modify, alter, change, amend. В электронном словаре Мультитран можно найти следующие примеры употребления этих глаголов. to modify the flight plan уточнять план полета, to alter the aircraft - дорабатывать конструкцию самолета; an amended clearance -уточненное разрешение; a change in engine trust -изменение тяги двигателя.

\section{Выво}

Именно научно-технические тексты содержат новейшую информацию о научных и технических достижениях, а, следовательно, отражают реальность сегодняшнего дня. В связи с этим, исследования в области научно-технического перевода занимают важное место в современной теории перевода [1, с. 205]. В наших более ранних работах мы уже неоднократно приходили к следующему выводу, что переводчик должен принимать во внимание ту область технического перевода, с которой он работает. Также он должен представлять, о чем именно данный текст перевода, самому вникать в технические особенности или же прибегать к консультации специалистов, чтобы оценить адекватность перевода, то есть учитывать непосредственно микро и макроконтекст, не только лингвистические особенности, но и экстралингвистические. [Анурова, 2016, с. 60]. Если переводчик намерен иметь специализацию в то или иной области перевода, то абсолютно необходимо, чтобы формировалась компетенция фоновых знаний, которую мы определяем как способность обеспечивать адекватность перевода на основе учёта приобретаемых культурологических знаний, знание происхождение общеупотребительных слов и терминов, их функциональных особенностей и первоначальном значении. [4, с. 57]. Также можно сделать вывод, что ряд синонимичных терминов, содержащихся в стандартах и технических документах, может расширяться или дополняться для тех или иных специальных целей. Одной из причин такой вариантности является употребление терминов в разных контекстах, что наиболее ярко проявляется на примерах из английского языка.

\section{ЛИТЕРАТУРА}

1. Аникеева И.Г., Овсянникова М.Н. Подготовка специалистов авиационного профиля к иноязычной профессиональной коммуникативной деятельности. Вестник Самарского государственного университета. 2015. № 4 (126). С. 205-210.

2. Анурова 0.М. Интернационализмы и их роль при переводе авиационно-технических текстов. Сборник докладов. Выпуск №8. - М.: Перо, 2016, - 422с.

3. Гринев-Гриневич С.В. Введение в терминографию: Как просто и легко составить словарь: учеб. пособие. 3-е изд., доп. М.: Книжный дом «ЛИБРОКОМ», 2009. $225 \mathrm{C}$.

4. Зубанова С.Г. Социальное служение в России: исторический опыт, теоретические основы и современная практика: монография - Москва, 2013. - 208 с.

5. Кронгауз М.А. Семантика: учебник. М.: Из-во РГГУ, 2001. 399 с.

6. Лейчик В.М. Терминоведение: Предмет, методы, структура. 5-е изд. М.: Книжный дом «ЛИБРОКОМ», 2012. 264 с.

7. Хижняк С.П. Когнитивная проблематика в общей теории термина: [монография]. Саратов: ИЦ «Наука», 2016. 172 с.

8. Longman. Словарь. [Электронный ресурc] https://www.Idoceonline.com/spellcheck/english/?q=SLIDING+TUBE (дата 0бращения: 25.08.2021)

9. Multitran. Словарь [Электронный ресурc] URL: http://www.multitran.ru (дата обращения: 18. 08.2021)

10. Airbus A-320/A-321 Flight Crew Operating Manual, 2020, 5692p.

๑ Анурова Ольга Михайловна (kokorewa@rambler.ru), Зудилова Екатерина Николаевна (e.n.zudilova@gmail.com).

Журнал «Современная наука: актуальные проблемы теории и практики» 